application the questions, "Am I or am I not a "lunatic'?" "Am I or am I not entitled to the relief offered here?" and turning sorrowfully away, unable or unwilling to admit the soft impeachment and being thereupon for ever afterwards a chronicled "lunatic."-I am, Sirs, yours faithfully,

West Malling, Kent, July 25th, 1903.

JAMES ADAM.

\section{THE TREATMENT OF GOITRE BY THE USE OF DISTILLED OR RAIN WATER.} To the Editors of THE LANCET.

SIRS, - With regard to the letters of Dr. C. A. Rayne and Dr. W. H. B. Brook in The LaNoet of July 18th (p. 185) and 25th (p. 265), I may say that the use of rain and distilled waters is no new thing in the treatment of goitre. It has been familiar to physicians in diverse parts of the world for a long time. Several cases of cure by this means have occurred in my own practice, as I pointed out in a paper read some years ago at Carlisle at a meeting of the Border Branch of the British Medical Association. I do not think that the cure depends on either rain or distilled water as a matter of fact, but on the fact that the patient is drinking a fluid free from the goitrous poison and in proof of this I may quote the following instance from the writings of St. Lager. "Keyssler says that round Schemnitz in Hungary the goitrigenous action of the waters is so evident that those who go to drink the water of a neighbouring valley have the satisfaction of seeing their tumours disappear." Many similar instances could be quoted. Here is an interesting one, also from St. Lager. "Military surgeons who have observed epidemics of goitre at Clermont and several other towns noticed that the officers and noncommissioned officers who only drank wine escaped the disease." It is a remarkable fact that goitre is unknown in places where rain water only is used-e.g., Constantinople, Venice, parts of Holland and Belgium, \&c. Cardinal Billiet has put on record a remarkable case of goitre incidence occurring in the village of Puiset in Planaise. Here he found 17 families more or less afflicted with goitre and cretinism from using the spring water of the country. One family was absolutely healthy and used rain-water only The best results are obtained, of course, in cases of recently formed goitres as when a considerable amount of fibrous tissue is formed the results are not so good although frequently remarkable.

I am, Sirs, yours faithfully.

Louis E. STEVenson, M.B., \&c., F.G.S.

Temple Sowerby, Penrith, July 25th, 1903.

\section{To the Editors of THE LANCET.}

SIRS, - The letters in the two last issues of THE LANCET on the use of distilled or rain water in goitre induce me to give briefly my own experience. For the last seven years I have directed patients with goitre to drink distilled water or boiled rain water. During this period I have treated about a dozen cases, some of them from other districts. I cannot say that all have been successful; one patient, a woman with a large goitre of many years standing, died; another took distilled water in considerable quantities for six months, but there was no improvement and she was finally cured by hydrofluoric acid. In this case $I$ am confident that the patient always took the distilled water and continued to do so for 18 months after her cure. Of the other cases all were wholly or partially cured, but I cannot be certain that they always carried out the treatment. The conclusion $I$ have come to is that distilled water is a valuable adjunct in the treatment of goitre, but not of itself a specific. It would be interesting to hear the experience of others on this point. I am, Sirs, yours faithfully,

Arthur O. Wilson, M.B., Ch.B. Vict.

Formby, July 26th, $19 \mathrm{c} 3$

\section{MEDICAL DOCTRINES OF HEREDITY.}

\section{To the Editors of THE LANCET.}

SIRS, - In The LaNCET of July 25th, p. 264, Dr. C. R. Niven takes me to task for having, as he conceives, misrepresented Dr. G. Archdall Reid's position as set forth in that gentleman's letter to you of July 4th, p. 56. Dr. Reid is, I am sure, well able to take care of himself and will be able to judge whether I have misconstrued his position, but I contend that the very passage which Dr. Niven quotes from Dr. Reid's letter fully bears out the construction put on it. Dr. Reid says : "Even if the germ cells are injured, it does not follow that this injury will be perpetuated in their very remote descendants -i.e., in the body cells of the child-at a time long after the injurious agency has ceased to act" and he implies his disbelief in the possibility of such injury being so perpetuated, his whole argument, indeed, being devoted to substantiating that position, which position, if correct, certainly implies that the germ plasm is incapable of receiving permanent iujury by the agency of poisons circulating in the blood-that is, of course, that the damage to individual germ cells is never of such a nature as to lead to permanent alteration in the organism which results therefrom. If any injury has been inflicted on the germ cells of a parent by the action of a poison circulating in the blood this can only be judged of by its effects on the offspring. Wither a modification can be produced in the somatic cells of a child as a result of such influence or it cannot. If as a result of the development of germ cells in a vitiated nutrient medium the child resulting therefrom is modified in any direction, however slight, then a definite germinal variation has been produced through the agency of the poison in question. If, however, the effect, if any, produced on the germ cells is always more or less evanescent, and if no permanent alteration can be produced in the somatic cells of the child thereby, then it necessarily follows that the child has not been modified in any way and that no harm of any kind has been produced. As the well-being of the offspring is the only thing with which we are here concerned it is a necessary conclusion that if this cannot be permanently injured by the action of poisons on the germ cells of the parent, then it is a matter of indifference as regards the welfare of such offspring whether the germ cells from which it arises are ceveloped in a vitiated nutrient medium or the reverse.

Dr. Niven devotes a portion of his letter to creating for me an imaginary position and then proceeding to criticise it. I suggested that there might be causes of variation other than those comprised in the union of two dissimilar germ plasms, the context clearly showing that I was referring to the possibility of such variation occurring by the direct action of poisons on the germ plasm; but Dr. Niven chooses to assume that I was arguing in favour of the transmission of acquired characters. I argued nothing of the sort and there is not a line in my letter suggesting any opinion of the kind. As a matter of fact, $I$ am entirely in harmony with Dr. Reid as to the non-transmission of acquired characters and have elsewhere ${ }^{1}$ expressed myself in favour of the view that on this question "the Weismannian position at present holds the field." It is therefore somewhat superfluous for Dr. Niven to ask me for proof of doctrine which I do not hold and which was in no way raised in my letter. Dr. Niven goes on to say that if injury is done to the growth of the embryo during the pregnancy of a drunken mother that is not a problem in heredity. I never suggested that it was. I have indeed elsewhere ${ }^{2}$ drawn attention to the fact that in these cases any injury done to the germ plasm "will be added to, and reinforced by, chronic alcoholic poisoning of the nervous centres of the embryo during the whole period of intra-uterine life." The condition of the mother during the intra-uterine life of the child is one of the disturbing factors which have to be taken into account in endeavouring to form an estimate as to the effect of poisons upon the germ plasm itself, but in the case of alcohol this disturbing factor can often be entirely eliminated as innumerable cases exist of the union of drunken fathers with sober mothers. I am not disputing the general position which Dr. Reid has so frequently insisted on and which Dr. Niven adopts-viz., that nations are sober in proportion to their past experience of alcohol. I think it probable that such an evolution of alcohol-resistant communities has been and is going on, though I would remind Dr. Niven of the striking example afforded by the Mohammedan races which show us millions of human beings who are perfectly sober not by virtue of such an evolution, but in consequence of the operation of religious sanctions. Where I differ from Dr. Reid and Dr. Niven is in the position they take up that an unfavourable variation such as would presumably be produced by the action of alcohol on the germ plasm of the parents would necessarily go on accumulating 
from generation to generation until the whole race became extinct. Whether it did go on so accumulating or not would depend largely upon the nature of the germ plasm with which it united in the act of fertilisation. Even when many molecules of one germ cell are modified in the direction of instability these may be counteracted and controlled by more stable molecules belonging to the other germ cell and the offspring thus conditioned may be free from taint; a degeneracy which has been begun may therefore be elimi. nated altogether in future generations. As a matter of fact, such a process of elimination of parental taint by reversion to a more stable ancestry is continually going on side by side with one which reinforces and adds to the degeneracy. There is a great tendency to regression towards the mean standard of the race, as Galion has shown us, and the more persistent nature of racial characters as compared with individual ones, whilst it renders progress of a healthy kind less rapid than it would otherwise be, has also a preservative influence in the opposite direction. I think that the inhabitants of the British Islands may fairly be described as "very drunken" ; nevertheless, it cannot, I think, be denied that we have abundance of stable germ plasms in our midst ready, it may be, to neutralise the unstable elements of other germ plasms, rendered such by the action of alcohol, or to supplant these latter altogether.

But, in truth, the laws of heredity are so intricate and we are still so ignorant of their mode of operation that dogmatism in either direction is out of place. The exact experiments which might, setitle the question cannot, of course, be conducted on the human subject; but it might be possible to obtain results of value by administering alcohol to some of the lower animals such as anthropoid apes or dogs and noting the effect on the progeny. It would, of course, be necessary to give the alcohol in sufficient quantity and for a long enough period of time to get the tissues thoroughly saturated with the poison-to simulate, in fact, the sodden tissues of the chronic alcoholic-and it should be stopped directly conception had been permitted to take place. The relatively undeveloped brains of these animals would render impossible an exact comparison with the human subject, but the experiment would be worth a trial.

In the meantime, I contend that the remarkable frequency with which alcoholism is found in the family antecedents of those who suffer from insanity or the milder forms of mental instability furnishes a primấfacie case against alcoholthat is, in favour of the view that the molecules of the germ cells of the parent are capable of having their development modified by the circulation of alcohol in the blood in such a way as to cause the organism resulting therefrom to develop on abnormal lines. Can Dr. Reid or Dr. Niven furnish evidence to show that on the average the children of alcoholic parentage are as stable and healthy as those of parents not so circumstanced ?-I am, Sirs, yours faithfully,

Rainhill, July 26th, 1903.

J. WIGLESWORTH.

\section{THE ROENTGEN RAYS IN THE DIAGNOSIS OF PULMONARY DISEASE.}

\section{To the Editors of THE LANCET.}

SIRS,-It is becoming customary on the part of those who are more or less enthusiastic over the $\mathrm{x}$ rays to assert that cases of pulmonary tuberculosis can be detected by these means at an earlier stage and with greater certainty than is possible by the time-honoured method of inspection, percussion, and auscultation in its various applications and refinements. In certain recent communications to THE LANCE'T $^{1}$ this view is upheld and it is therefore with pleasure that one turns to the article of Dr. David Lawson and Mr. Hill Crombie ${ }^{2}$ in which a temperate and carefully expressed opinion is pronounced as to certain facts elicited by radioscopy. As, however, the claims put forward by some on behalf of the $x$ rays are such as might lead the unwary to imagine that it is absolutely necessary for them to procure an $x$ ray apparatus in order to do justice to their patients and themselves, I venture to express the opinion that not only are the $x$ rays as a means of diagnosis in early phthisis less valuable and less exact than the ordinary methods, but that in addition, what results they do yield are very frequently unreliable and at the best are difficult of interpretation.

Now, this statement is not made in any spirit of prejudice against the recent science of radioscopy. In the

1 The LANCET, June 27th (p. 1800) and July 4th (p. 55), 1903. 2 THE LANCET, July 25th, 1903, p. 212 .
The June 27 th hands of those who have had long practice in its use it is frequently of excellent service in many intrathoracic conditions, more especially in the case of deep-seated tumours, and also, it may be added, as an aid in the diagnosis of pulmonary tuberculosis, but as regards its superiority in the detection of the earliest stage of phthisis statements of a delusive character are being made.

I may preface the brief observations which follow by observing that $x$-ray workers do not, as a rule, detail the examination by percussion, auscultation, \&c., which they have conducted in order to check the results of radioscopy in the diagnosis of early tuberculosis. It may be stated that over a certain area, such and such a note was all that could be elicited, or that the breath sounds were doubtfully so and so, but for anything like a minute, systematic, and exhaustive examination one usually searches their records in vain. But it such a careful detailed examina. tion be not recorded alongside the results of radioscopy, then these results are valueless as comparative data, however confident the assertions based on them.

It is admitted by all radioscopists that it is only in the stage of consolidation, or in other words, after a number of tubercles have fused together so as to form a caseous mass in the lung, that the rays are of any service. Dr. Lawson remarks that the earliest reliable indication of disease affecting an apex is its "failure to light up on the screen at full inspiration to the same extent as the non-affected apex does. "This negative quality," he says, "is absolutely diagnostic, either of an active or an arrested lesion. This property also enables one to define the level of the apex of the lungs on each side respectively - a point in diagnosis to which many attach much importance." Now it can scarcely be supposed that the most devoted adherent of $x$-rayism would allege that such an apex was insusceptible of ordinary diagnosis. On the other hand, I should say that refined tests would indicate commencing involvement of an apex at a considerably earlier stage than that above described, and indeed at a time which may be called pre-tuberculousi.e., when there is merely comparative impairment of the elasticity of one lung. Such diagnostic tests include the various methods of estimating and comparing the apical excursion on both sides and the "segmental" method as described by the writer. ${ }^{3}$ Such tests, also, can differentiate with certainty between an active and an arrested lesion, which, as Dr. Lawson observes, cannot be effected by the $x$ rays.

A sign which has been made much of by radioscopists as denoting either the pre-tuberculous stage or else the deposition of isolated tubercles is a restriction in the excursion of the diaphragm on one side during deep inspirations. It may be true that this phenomenon has obtained prominence since the introduction of radioscopy, but whatever value is to be attached to it, it can be determined with perfect accuracy by the following means : (1) by inspectionLitten's sign-when, with the patient lying in the correct position against the light, the diaphragm shadow can be seen as a thin dark line moving up and down the side of the chest; (2) by percussion, in the form of "limitary percussion" *; (3) by auscultation, especially the vocal resonance, the patient having first drawn a deep breath and the stethoscope moved upwards as he expires and counts audibly ; and (4) by auscultatory resonance, by means of a tuning fork, a delicate test by which, with the stethoscope placed over the organ and the tuning fork brought towards it, the edge of the lung can be sharply demarcated during inspiration and expiration. These manouvres, in the hands of those who have practised them, will define the diaphragm excursion as accurately as the $x$ rays. It is, however, to be noted that this "diaphragm sign" is variable, not always trustworthy, and certainly not applicable to all cases. It is easy to see that basal conditions affect it greatly and the same, though to a much less extent, may be said of certain abdominal conditions. First described by F. H. Wiliiams of Boston several years ago and largely quoted since, that acute observer pointed out two facts worth remembering: one that in the healthy chest the excursion on the right side is normally greater in forced inspiration than that on the left side, and the other, that in certain early cases of tuberculosis, although the inspiratory excursion was shortened on the affected side, yet in forced expiration the diaphragm rose higher on the diseased side, in this way the range being about equal on the two sides. 